\title{
Effect of Six Months of Aerobic Exercise on Lipid Profile, Inflammatory Markers and Risk Factors of Cardiovascular Disease in Obese Women
}

\author{
Mahtab Moazami (PhD) \\ Department of Exercise \\ Physiology, Faculty of Physical \\ Education and Sport Sciences, \\ Ferdowsi University of Mashhad, \\ Mashhad, Iran
}

Asra Askari (PhD)

Department of Physical Education and Sport Sciences, Gorgan

Branch, Islamic Azad University, Gorgan, Iran

Corresponding author: Mahtab Moazami

Tel: +989153156705

Email: mahtab.moazami@gmail.com

Address: Faculty of Physical

Education and Sport Sciences, Ferdowsi University of Mashhad, Mashhad, Iran

Received : 04 May 2015

Revised: 01 Nov 2017

Accepted: 23 Nov 2017

Mahtab Moazami 0000000264222935
ABSTRACT

Background and objectives: The aim of this study was to investigate the effects of six months of aerobic exercise on lipid profile, inflammatory markers, and risk factors of cardiovascular disease in middle-aged obese women.

Methods: Fifteen obese woman (age range: 35 to 45 years) with BMI of $\geq 30 \mathrm{Kg} / \mathrm{m}^{2}$ were enrolled via purposeful and convenience sampling. The participants were randomly divided into training $(\mathrm{n}=10)$ and control $(\mathrm{n}=5)$ groups. Blood samples $(7 \mathrm{ml})$ were taken from all participants before the first training session and after the last training session. The women performed 60 minutes of aerobic exercise at $55-65 \%$ of heart rate reserve, three sessions a week, for six months. Data was analyzed using independent and paired t-tests and Mann-Whitney $\mathrm{U}$ and Wilcoxon tests at significance of 0.05 .

Results: After the six-month aerobic exercise, C-reactive protein, low-density lipoprotein, triglycerides, total cholesterol and high-density lipoprotein/total cholesterol decreased significantly. The exercise intervention also caused a significant increase in the concentrations of high-density lipoprotein and apolipoprotein A.

Conclusion: Aerobic exercise can reduce the level of inflammatory markers associated with risk of cardiovascular disease and atherosclerosis.

Keywords: Lipid profile, Inflammatory markers, Obese women, Apolipoprotein, Aerobic exercise. 
The metabolic triad (hyperinsulinemia, hyperapolipoprotein B, and low-density lipoprotein) is among the risk factors that have recently attracted a lot of attention (1). Numerous studies have shown that the metabolic triad is an important predictor of cardiovascular disease (1). Obesity and overweight are the independent risk factor for atherosclerosis (2). Body mass index (BMI) of more than $25 \mathrm{Kg} / \mathrm{m}^{2}$ and $30 \mathrm{Kg} / \mathrm{m}^{2}$ is defined as overweight and obesity, respectively (3). Indeed, individuals with visceral obesity have impaired plasma lipid metabolism including increased triglycerides (TGs) and apolipoprotein B (ApoB) and low-density lipoprotein-cholesterol (LDL-C), and decreased high-density lipoprotein-cholesterol (HDL-C) levels (4). Generally, accumulation of abdominal and visceral fat is associated with an increased risk of thrombosis and elevation of inflammatory markers, all of which contribute to the development of unstable atherosclerotic plaques and unstable angina pectoris. Therefore, stabilization and fixation of atherosclerotic plaques have an important role in reducing the risk of cardiovascular events in obese individuals (5). With increasing prevalence of obesity, the research on strategies to tackle obesity and cardiovascular disease and associated metabolic risk factors have increased considerably. The main risk factors for coronary heart disease in women are insulin resistance, high waist-to-hip ratio, lipid and fatty acid oxidation disorders, inappropriate HDL and LDL concentrations, unfavorable apolipoprotein A1 (ApoA1) and ApoB levels, sedentary lifestyle, inappropriate diet, obesity, smoking, hypertension, and stress (6).

Several studies have identified the role of local and systemic inflammation in the process of atherosclerosis and its complications (7). Therefore, several plasma inflammatory markers such as C-reactive protein (CRP) have been introduced to predict the risk of coronary events (9). Research has shown that elevation of CRP causes a 2- to 5-fold increase in the risk of coronary artery disease (10). CRP measurement can facilitate diagnosis of acute myocardial infarction, type 2 diabetes, coronary heart disease, inflammation, and diseases that cannot be diagnosed through clinical examination (7).
Exercise, physical activity, and endurance training can act as therapeutic factors for patients with atherosclerosis (11). Recent studies show that regular exercise can lower LDL levels by $5 \%$ and subsequently increase HDL by 3 to $6 \%$ (12).

Long-term exercise directly reduces CRP levels by decreasing cytokine production in adipose tissue, muscles, and mononuclear cells and increasing insulin sensitivity, all of which contribute to weight loss and improvement of endothelial function (13). In recent years, the protein component of lipoproteins has attracted the attention of researchers, and many studies have shown that serum levels of HDL and LDL depend on the production of ApoA and ApoB. In addition, ApoA and ApoB levels have a negative and positive correlation with risk of cardiovascular disease, respectively (14). Hence, this study evaluated the effects of six months of aerobic training on lipid profile, inflammatory markers, and cardiovascular risk factors in middle-aged obese women (with BMI of $\geq 30$ ).

\section{MATERIAL AND METHODS}

Fifteen obese woman (age range: 35 to 45 years) with BMI of $\geq 30 \mathrm{Kg} / \mathrm{m}^{2}$ were enrolled via purposeful and convenience sampling. After obtaining consent and completion of a health questionnaire, the participants were randomly divided into training $(\mathrm{n}=10)$ and control $(n=5)$ groups. Exclusion criteria included drug use, menopause, smoking, and regular exercise in the last six months. First, anthropometric characteristics such as height, weight, and BMI of the women were recorded. Then, they participated in a briefing before the start of the training protocol. To evaluate the variables under study, fasting blood samples ( 7 $\mathrm{ml}$ ) were taken from all participants in a sitting position before the first training session (pretest) and after complication of the last training session (post-test).

The women performed 60 minutes of aerobic exercise, three sessions a week, for six months. The exercise protocol included walking, jogging, and aerobic movements at 55-65\% of heart rate reserve. The intensity of exercise was controlled along the study. The control group did not perform any antivity Tre total sholactarnl (Tr), HDL, ured by

\section{INTRODUCTION}


spectrophotometry using the BS-380 chemistry analyzer (Mindray Co, China). Serum CRP level was measured by enzyme-linked immunosorbant assay (ELISA) using commercial kits (Monobind Inc, USA). ApoA and ApoB values were measured using biochemical kits (Pars Azmun, Iran) and a Hitachi 902 autoanalyzer. Data was analyzed using descriptive statistics in SPSS (version 18); The Shapiro-Wilk test was used to assess normality of data; Independent and paired ttests were used for evaluation of intra-group and inter-group changes in LDL, ApoB, TC, HDL, HDL/TC, and TG levels; The MannWhitney $\mathrm{U}$ test and Wilcoxon rank-sum tests were used for analysis of ApoA and CRP due to non-normality of data. All statistical analyses were performed at statistical significance of 0.05 .

\section{RESULTS}

Table 1 shows the characteristics of the participants in the study groups. The results of t-test showed that after the six-month aerobic exercise, LDL, TG, TC, and HDL/TC levels decreased significantly, while HDL level increased significantly (Table 2).

Although the ApoB value decreased in the training group, this decrease was not statistically significant (Table 2 ).

After the six-month training intervention, there was a significant difference in HDL, TC, and HDL/TC values between the training and control groups.

However, there was no significant difference between the two groups in terms of LDL, TG, and ApoB levels (Table 3).

The Mann-Whitney $U$ test showed a significant difference in CRP values between the two groups. However, ApoA values had no significant difference between the two groups (Table4). The Wilcoxon test also showed a significant decrease in CRP and a significant increase in ApoA levels (Table 4).

Table 1- Characteristics of the subjects in the training and control groups

\begin{tabular}{ccc}
\hline Variable & Training group & Control group \\
\hline Height $(\mathrm{cm})$ & $\mathbf{1 5 6 . 0 0} \pm 5 / 033$ & $\mathbf{1 5 7 . 0 0} \pm \mathbf{3 . 6 0 6}$ \\
Weight $(\mathrm{Kg})$ & $\mathbf{8 0 . 5 3} \pm 9.224$ & $\mathbf{7 7 . 7 8 0} \pm 7 / 074$ \\
Age $(\mathrm{year})$ & $\mathbf{4 1 . 7 0} \pm \mathbf{3 . 1 9 8}$ & $\mathbf{4 3 . 4 0} \pm \mathbf{1 . 5 1}$ \\
BMI $\left(\mathrm{Kg} / \mathrm{m}^{2}\right)$ & $\mathbf{3 1 . 7} \pm \mathbf{5 . 4}$ & $\mathbf{3 0 . 8} \pm 6.3$ \\
\hline
\end{tabular}

Data are shown in mean \pm standard deviation (SD)

Table 2- Mean \pm SD of lipid and apolipoprotein profiles in the training group

\begin{tabular}{|c|c|c|c|}
\hline Index & Pre-test & Post-test & P-value \\
\hline LDL-C (mg/dl) & $112.10 \pm 7.76$ & $99.20 \pm 13.84$ & $* 0.00$ \\
\hline HDL-C (mg/dl) & $43.10 \pm 2.28$ & $46.10 \pm 1.37$ & ${ }^{*} 0.01$ \\
\hline TC (mg/dl) & $227.50 \pm 18.25$ & $187.10 \pm 22.06$ & ${ }^{*} 0.00$ \\
\hline TG (mg/dl) & $193.30 \pm 56.79$ & $171.20 \pm 36.71$ & $* 0.03$ \\
\hline $\begin{array}{c}\text { HDL/TC (ratio } \\
\text { factor) }\end{array}$ & $5.30 \pm 0.64$ & $4.06 \pm 0.48$ & ${ }^{*} \mathbf{0 . 0 0}$ \\
\hline ApoB (mg/dl) & $97.10 \pm 17.01$ & $96.20 \pm 16.26$ & 0.48 \\
\hline BMI $\left(\mathrm{Kg} / \mathrm{m}^{2}\right)$ & $31.7 \pm 5.4$ & $28.24 \pm 2.3$ & ${ }^{*} 0.00$ \\
\hline Weight (Kg) & $80.53 \pm 9.224$ & $66.20 \pm 5.346$ & $* 0.00$ \\
\hline
\end{tabular}

Table 3- Comparison of mean \pm SD of lipid and apolipoprotein profiles between the training and control group in the post-test

\begin{tabular}{cccc}
\hline Index & Control group & Training group & P-value \\
\hline LDL-C (mg/dl) & $112.40 \pm 7.56$ & $99.20 \pm 13.84$ & 0.07 \\
HDL-C (mg/dl) & $41.40 \pm 1.14$ & $46.10 \pm 1.37$ & ${ }^{*} 0.00$ \\
TC (mg/dl) & $218.00 \pm 27.82$ & $187.10 \pm 22.06$ & ${ }^{*} 0.03$ \\
TG (mg/dl) & $185.80 \pm 20.69$ & $171.20 \pm 36.71$ & \\
HDL/TC (ratio & $5.26 \pm 0.59$ & $4.06 \pm 0.48$ & $* 0.001$ \\
$\begin{array}{c}\text { factor) } \\
\text { ApoB (mg/d) }\end{array}$ & $105.20 \pm 10.32$ & $96.20 \pm 16.26$ & 0.28 \\
\hline
\end{tabular}


Table 4- Levels of ApoA and CRP in the training and control groups

\begin{tabular}{cccc}
\hline Test & Index & U-value & P-value \\
\hline Mann-Whitney U & ApoA (mg/d) & $\mathbf{1 9 . 5 0}$ & $\mathbf{0 . 5 1 3}$ \\
test & CRP & 7.50 & $* 0.028$ \\
Wilcoxon test & ApoA (mg/dl) & Z-value & P-value \\
& & -2.492 & $* 0.013$ \\
& CRP & -2.375 & $* 0.018$ \\
\hline
\end{tabular}

\section{DISCUSSION}

The six-month aerobic training exercise significantly affected the indices investigated in the study. The training program caused a significant reduction in the levels of LDL, TG, TC, HDL/TC, CRP, and ApoA. It also caused a significant increase in HDL and a nonsignificant decrease in ApoB levels. We also observed significant differences in the HDL, TC, and HDL/TC post-test values of the two study groups, but there was no significant difference in the LDL, TG, and ApoB values between the two groups. These results are in line with some studies $(8,15-17)$ and inconsistent with a few other studies (18-20). Increased LDL level is an independent risk factor for coronary artery disease, and its reduction to $60 \mathrm{mg} / \mathrm{dl}$ will reduce the incidence of coronary artery disease by $50 \%$ within two years (21). Based on previous studies, LDL has a greater oxidation potential and is influenced by oxidizing materials, macrophages, endothelial cells, and vascular smooth muscle cells. This process leads to formation of foam cells, subsequently promoting the formation of atheroma (14).

The increase in TG levels is one of the mechanisms associated with increased HDL catabolism, resulting in formation of TG-rich particles, which act as suitable substrates for hepatic lipase. HDL not only has a role in reverse cholesterol transport, but also acts as an antioxidant, anti-inflammatory and antithrombotic agent that improves endothelial function by controlling endothelial cell apoptosis (22). Initiation of atherosclerosis is largely dependent on the oxidation of LDL, which could be inhibited by HDL (14).

There is a significant relationship between ApoB level and severity of coronary artery disease. This can be attributed to the fact that the atherogenic particles such as VLDL, intermediate-density lipoprotein and LDL have ApoB molecules, which directly present the amount of atherogenic plasma lipoproteins. However, no significant relationship has been found between ApoA level and severity of coronary artery disease (23). ApoA is the main protein component of HDL, which is produced by the small intestine and liver. Increased ApoA production stimulates the formation of new HDL particles (23). Various studies have shown that ApoB is the major component of LDL-C and VLDL, and the interaction of ApoB with the LDL-C receptor plays an important role in its uptake from peripheral and hepatic cells (23).

It has been reported that polymorphisms in the ApoB gene are associated with TC and ApoB concentrations (24). In clinical conditions, HDL-C and ApoA have anti-atherogenic properties. Furthermore, the plasma concentration of ApoB indicates the total number of potentially atherogenic particles, correlating with the non-HDL-C levels. The ApoB/ApoA ratio is a better indicator of the risk of coronary artery disease compared to LDL-C. A study reported that physical activity can effectively decrease body fat percentage, and increased ApoB metabolism can affect LDL metabolism (25). Variation in circulating concentrations of factors such as lecithin cholesterol acyltransferase, acyl-CoA cholesterol acyltransferase, cholesteryl ester transfer protein, and phospholipid transfer protein due to exercise activity can affect the concentration of ApoA (26). Exercise not only reduces the amount of $\mathrm{TC}$, but also increases HDL-C and lowers LDL-C levels. Regular physical activity also increases cardiac workload, resulting in feelings of pleasure and happiness. The intensity of physical activity is one of the most important factors affecting the HDL levels (15). According to previous studies, exercise and physical activity increase HDL levels and decrease LDL oxidation, ultimately reducing the risk of cardiovascular disease. In other words, increasing the diameter of LDL lowers its permeability at the plasma-arterial wall interface and consequently its accumulation and atherogenesis. However, it should be noted that LDL metabolism and the risk of cardiovascular disease increase in intense exercise (at intensity of $>80 \%$ of maximal 
aerobic power) $(8,27)$. Several studies have shown that physical activity reduces the concentration of LDL, which is thought to be linked with exercise intensity (28). Improvement of lipid profile in our participants is partially due to the role of estrogen in the elevation of HDL levels, which decreases LDL-C concentration and fat lipid deposition in the arterial wall (28).

We also observed a significant decrease in CRP values following the six-month aerobic training exercise. This finding is in line with some studies $(29,30)$ but inconsistent with studies of Lee et al. and Leon and Sanches (31, 33). According to research, CRP level is a stronger predictor of cardiovascular events than the LDL level, and the risk of heart attack in people with a CRP greater than $2.11 \mathrm{mg} / \mathrm{L}$ is three times higher than those with CRP value of no more than $0.55 \mathrm{mg} / \mathrm{L}$. It has been well established that high CRP values are strongly related to obesity (33). Generally, total adipose tissue is higher in women than in men, and there is strong evidence suggesting that inflammatory markers are associated with abdominal obesity (34). Long-term exercise leads to CRP reduction by reducing cytokine production in adipose tissue, muscles, and mononuclear cells, and increasing insulin sensitivity, which subsequently improves

\section{REFERENCES}

1. Despres JP. Health consequences of visceral obesity. Annals of Medicine. 2001; 33(8): 534-41.

2. Nadimi M. Heaithy heart: What must Know general: A Guide to cognition and preventing heart diseases. $3^{\text {th }}$ ed. Sales Pub. 2009; 145-168. [Persian]

3. Spiegelman BM, Flier JS. Obesity and the regulation of energy balance .Cell. 2001; 104(4): 531-43.

4.Despres JP, Pascot A, lemieux I. Risk factors associated with obesity: a metabolic perspective. Ann Endocrinol . 2000; 61 suppl 6: 31-38.

5. Despres JP, lemieux I, Dagenais GR, Cantin B, Lamarche B. Evaluation and management of atherogenic dyslipidemia: beyond low-density lipoprotein cholesterol. CMAJ. 2002; 165(10): 1331-1333.

6. Braith RW, Stewart KJ. Resistance exercise training: Its role in the prevention of cardiovascular disease. Circulation. 2006; 113(22): 2642-50.

7.Dehghan A, Kardys I, de Maat MP, Uitterlinden AG, Sijbrands EJ, Bootsma AH, et al. Genetic Variation, $C$ reactive Protein Levels, and Incidence of Diabetes. Diabetes. 2007; 56(3): 872-9. [Persian]

8. Koozehchian MS, Nazem F, Kreider RB, Roberts WJ, Best TM, Rong Y, Zuo L. The role of exercise training on lipoprotein profiles in adolescent males. Lipids Health Dis. 2014; 13(1): 95. doi: 10.1186/1476-511X-1395. endothelial function (35). In this regard, a study showed that lack of CRP reduction after exercise could be due to lack of change in adipose tissue and insufficient exercise duration (36). Recent studies show that regular and prolonged exercise reduces CRP levels through several mechanisms. Given that CRP increases significantly in the course of inflammation and it is accompanied by a notable increase in plasma IL-6 concentrations, it seems that one of the reasons for the increased CRP value in obese people is the overproduction of IL- 6 , which triggers CRP production. Increased mechanical stress and activation of endothelial cells could be among the possible causes of increase in CRP values (37).

\section{CONCLUSION}

Performing aerobic exercise can reduce the inflammatory markers associated with risk of cardiovascular disease and atherosclerosis. Given that most inflammatory markers are closely linked to obesity, performing such exercises for weight loss can be beneficial for obese individuals.

\section{ACKNOWLEDGMENTS}

The authors of would like to thank all those who have contributed to this study.

9. Hansson, GK. "Inflammation, atherosclerosis, and coronary artery disease". N Engl J Med. 2005; 352(16): 1685-1695.

10. Olson TP, Dengel DR, Leon AS, Schmitz KH. Changes in inflammatory biomarkers following one-year of moderate resistance training in overweight women. Int J Obes (Lond). 2007; 31: 996-1003.

11. Wang JS, Chow SE. Effects of exercise training and detraining on oxidized low-density lipoproteinotentiated platelet function in men. Arch Phys Med Rehabil 2004; 85(9):1531-7.

12. Volaklis KA, Spassis AT, Tokmakidis SP. Land versus water exercise in patients with coronary artery disease: effects on body composition, blood lipids, and physical fitness. Am Heart J 2007; 154(3): 560-566.

13.Nicklas BJ, Hsu FC, Brinkley TJ, Church T, Goodpaster BH, Kritchevsky SB, et al. Exercise training and plasma $C$-reactive protein and interleukin- 6 in elderly people. J Am Geriatr Soc. 2008; 56(11): 2045-52. doi: 10.1111/j.1532-5415.2008.01994.x.

14.Ding D, Li X, Qiu J, Li R, Zhang Y, Su D, et al. Serum Lipids, Apolipoproteins, and Mortality among Coronary Artery Disease Patients. Biomed Res Int Epub. 2014; 2014: 709756. doi: 10.1155 /2014/709756. 
15. Khajei R, Soltani M, Hejazi S m, Nematolahi S N, Zendedel A, Ashkani far. The effect of aquatic aerobics exercises on some of cardiovascular risk factors in patients with multiple scleroesis. http://osub.mums.ac.ir/osub/nilfr/njmsnm/index.php. Article 6, Volume 2, Issue 1, Spring 2012, Page 65-74. (persian)

16. Holme I, Hostmark AT, Anderssen SA. ApoB but not LDL-cholesterol is reduced by exercise training in overweight healthy men. Results from the 1-year randomized Oslo diet and exercise study. J Intern Med 2007; 262(2): 235-243. DOI:10.1111/j.13652796.2007.01806.x.

17. Paoli A, Pacelli QF, Moro T, Marcolin G, Neri M, Battaglia G, Sergi G, Bolzetta F, Bianco A. Effects of high-intensity circuit training, low-intensity circuit training and endurance training on blood pressure and lipoproteins in middle-aged overweight men. Lipids Health Dis. 2013; 12:131.

18.Ramalho AC, de Lourdes Lima M, Nunes F, Cambuí $\mathrm{Z}$, Barbosa C, Andrade A, et al. The effect of resistance versus aerobic training on metabolic control in patients with type-1 diabetes mellitus. Diabetes Res Clin Pract 2006; 72(3): 271-276. DOI:10.1016/j.diabres.2005.11.011.

19. Esfaranjani F, Rashidi F, Mardani SM. The EffectT of Aerobic Exercise on blood glucose, lipid profile and APO B-100 in patients with type II diabetes. Journal of ardabil university of medical sciences (JAUMS) summer 2013; 13(2):132-141. [Persian]

20. Haghighi AH, Yaghoubi M, Hosseini kakhk SAR. The Effect of Eight Weeks Aerobic Training and Green Tea Supplementation on Body Fat Percentage and Serum Lipid Profiles in Obese and Overweight Women. Medical Journal of Mashhad University of Medical Sciences. 2013; 56(4): 211-218. [Persian]

21. Law MR, Wald NJ, Rudnicka AR. Quantifying effect of statins on low density lipoprotein cholesterol, ischaemic heart disease, and stroke: systematic review and meta-analysis. BMJ 2003; 326(7404): 1423. DOI:10.1136/bmj.326.7404.1423.

22-Zois CE, Tokmakidis SP, Volaklis KA, Kotsa K, Touvra AM, Douda E, et al. Lipoprotein profile, glycemic control and physical fitness after strength and aerobic training in post-menopausal women with type 2 diabetes. Eur J Appl Physiol. 2009; 106(6): 901-7. doi: 10.1007/s00421-009-1078-6.

23.Mashaykhi N, Sadrneya S, Acherei A, Javaheri J, ahmadlou M. The correlation between serum Apo lipoprotein Al and Apo lipoprotein B with coronary artery disease and its severity. Arak University of Medical Sciences Journal. 2013; 16(6): 75-83. [Persian]

24.Daneshpour M, Faam B, Hedayati M, Azizi F. Presence of the $X+$ Allele in Apolipoprotein B Gene Increase the Total Cholesterol and Apolipoprotein $B$ Concentration in Tehranian People. Iranian Journal of Endocrinology and Metabolism. 2011; 12(6): 588593.[Persian]

25.Makaridze Z, Giorgadze E, Asatiani K. Association of the apolipoprotein b/apolipoprotein a-I ratio, metabolic syndrome components, total cholesterol, and low-density lipoprotein cholesterol with insulin resistance in the population of georgia. Int $\mathrm{J}$ Endocrinol. 2014;2014:925650. doi: 10.1155/2014/925650.
26.Lee J, Cho JY, Kim WK. Anti-inflammation effect of Exercise and Korean red ginseng in aging model rats with diet-induced atherosclerosis. Nutr Res Pract. 2014; 8(3): 284-91. doi: 10.4162/nrp.2014.8.3.284.

27. Ramezanpour MR, Hejazi SM, Hosseinnezhad M. The Comparison of HS-CRP, TG, LDL-c and HDL-c in Active and Non Active Middle-aged Women. Medical Journal of Mashhad University of Medical Sciences. 2013; 56(2): 93-98. [Persian]

28.Zolfaghary M, Taghian F, Hedayati M. Comparing the effect of green tea extract consumption, aerobic exercise and combination of these two methods on CRP Level in obese women. Razi Journal of Medical Sciences. 2013; 20(110): 8-21. [Persian]

29. Shih KC, Janckilab AJ, Kwok CF, Ho LT, Chou YC, Chao TY. Effects of exercise on insulin sensitivity, inflammatory cytokines, and serum tartrate-resistant acid phosphatase 5 a in obese Chinese male adolescents. Metabolism Clinical and Experimental Metabolism. 2010; 59(1):144-51. doi: 10.1016/j.metabol.2009.06.035.

30.Taghian F. Homocystein and $C$-reactive protein response to acute training in obese and non-obese females. Quarterly of Ofoghe Danesh. 2012;18(3): 129134. [Persian]

31. Lee YH, Song YW, Kim HS, Lee SY, Jeong HS, Suh $\mathrm{SH}$, et al. The effects of an exercise program on anthropometric, metabolic, and cardiovascular parameters in obese children, Korean Circ J. 2010; 40(4):179-84. doi: 10.4070/kcj.2010.40.4.179.

32. Okita K, Nishijima H, Murakami T, Nagai T, Morita $\mathrm{N}$, Yonezawa $\mathrm{K}$, et al. Can exercise training with weight loss lower serum C-reactive protein levels? Arterioscler Thromb Vasc Biol. 2004; 24(10): 1868-73.

33. Leon AS, Sanches OA. Response of blood lipids to exercise training alone or combined with dietary intervention. Med Sci Sports Exerc. 2001; 33(6 suppl):S502-S515.

34. Kelly AS, Steinberger J, Olson TP, Dengel DR. In the absence of weight loss, exercise training does not improve adipokines or oxidative stress in overweight children. Metabolism. 2007; 56(7): 1005-9.

35. Khazraee Ganji Far Z, Mabani M, Sokhanvar Dastjerdi sh .A comparison of HS-CRP, triglycerides and cholesterol inflammatory markers in active men after eccentric. International Journal of Sport Studies. 2016; Vol., 6 (5), 277-281.

36. Reed JL, De Souza MJ, Williams NI. Effects of Exercise Combined with Caloric Restriction on Inflammatory Cytokines. Appl Physiol Nutr Metab. 2010; 35(5):573-82. doi: 10.1139/H10-046.

37. Danzig V, Míková B, Kuchynka P, Benáková H, Zima $\mathrm{T}$, Kittnar $\mathrm{O}$, et al. Levels of Circulating Biomarkers at Rest and after Exercise in Coronary Artery Disease Patients. Physiol Res 2010; 59(3): 38592. 